\title{
La incidencia de la edad y el género en los hábitos de uso de las redes sociales en la profesión periodística. El caso de centenials y milenials
}

\section{The incidence of age and gender on social media usage habits in the journalism profession. The case of centennials and millennials}

María Ganzabal Learreta. Universidad del País Vasco UPV/EHU. España.

maria.ganzabal@ehu.eus

$[\mathrm{CV}] \oplus \mathrm{R}^{\mathrm{C}}$

Koldobika Meso Ayerdi. Universidad del País Vasco UPV/EHU. España.

koldo.meso@ehu.eus

$[\mathrm{CV}]$ G

Jesús Pérez Dasilva. Universidad del País Vasco UPV/EHU. España.

jesusangel.perez@ehu.eus

[CV] (1) $\mathrm{G}$

Terese Mendiguren Galdospin. Universidad del País Vasco UPV/EHU. España. terese.mendiguren@ehu.eus

\section{$[\mathrm{CV}]$ (1) $\mathrm{R}^{\mathrm{6}}$}

Este texto forma parte de la producción académica del proyecto de investigación US18/06, financiado por la Universidad del País Vasco y titulado: Perfiles digitales de los periodistas vascos y diálogo con las audiencias. La duración de este proyecto ha sido del 18.12.2018 al 17.12.2020.

Cómo citar este artículo / Referencia normalizada

Ganzabal-Learreta, M., Meso-Ayerdi, K., Pérez Dasilva, J., y Mendiguren Galdospin, T. (2021). La incidencia de la edad y el género en los hábitos de uso de las redes sociales en la profesión periodística. El caso de centenials y milenials. Revista Latina de Comunicación Social, 79, 91116. https://www.doi.org/10.4185/RLCS-2021-1525

\section{RESUMEN}

Las redes sociales han influido en la forma de consumir la información, pero también en la forma en la que el periodismo se adapta a nuevos públicos y a nuevas maneras de acceder a esa información. Para conocer cómo se utilizan estas aplicaciones sociales en los medios, se confeccionó un cuestionario, desde la perspectiva de género, teniendo en cuenta la desigualdad estructural entre hombres y mujeres periodistas. Este sondeo se aplicó a los profesionales de los medios de comunicación del País Vasco diferenciando entre grupos de edades, haciendo especial hincapié en las generaciones centenials y milenials. Se analizaron las cuatro redes sociales más utilizadas en España en 2020 además de otras aplicaciones y recursos multimedia. Los resultados de las más de 500 encuestas nos muestran un panorama donde el uso de las redes sociales está plenamente asentado en las redacciones. No encontramos especiales sesgos generacionales en el uso de las principales herramientas sociales. Las mujeres periodistas son las que emplean mayoritariamente las redes 
sociales y las más utilizadas son Twitter, Facebook e Instagram en detrimento de otras como Telegram, Linkedin o diferentes recursos audiovisuales. El conocimiento y la confianza son las principales causas de la primacía de unas sobre otras. Recomendamos a los medios de comunicación especificar la estrategia en redes sociales, formar a los profesionales y conseguir iniciativas de interés periodístico multimedia y transmedia hacia nuevas redes sociales como Tik Tok o Twitch.

PALABRAS CLAVE: periodistas, género, redes sociales, milenials, centenials.

\begin{abstract}
Social networks have influenced the way information is consumed, but also the way in which journalism adapts to new audiences and new ways of accessing information. To find out how these social applications are used by the media, a questionnaire was prepared from a gender perspective, taking into account the structural inequality between men and women journalists. This survey was applied to media professionals in the Basque Country, differentiating between age groups, with special emphasis on the centennial and millennial generations. The four most used social networks in Spain in 2020 were analyzed, as well as other applications and multimedia resources. The results of the more than 500 surveys show that the use of social networks is fully established in newsrooms. We found no special generational biases in the use of the main social tools. Women journalists are the ones who mostly use social networks and the most used are Twitter, Facebook and Instagram to the detriment of others such as Telegram, Linkedin or different audiovisual resources. Knowledge and trust are the main reasons for the primacy of some over others. We recommend the media to specify the strategy in social networks, train professionals and get initiatives of multimedia and transmedia journalistic interest towards new social networks such as Tik Tok or Twitch.
\end{abstract}

KEYWORDS: journalists, gender, social networks, millennials, centennials.

\title{
CONTENIDO
}

1.Introducción. 2. Estado de la cuestión. 3. Objetivos e hipótesis. 4. Metodología. 5. Resultados. 5.1. Herramientas y aplicaciones de mensajería para ejercer el periodismo. 5.2. Redes sociales utilizadas en el trabajo diario. 5.3 Recursos audiovisuales y blogs. 5.4. Beneficios del uso de redes sociales en el periodismo. 5.5. Riesgos y amenazas del uso de redes sociales en el periodismo. 6. Discusión y conclusiones. 7. Bibliografía.

\section{Introducción}

Han pasado más de veinte años desde que en 1998 se realizó el último estudio que analizaba la profesión periodística en Euskadi desde los medios de comunicación. Los resultados de aquella investigación arrojaban unos datos donde poco más de la mitad de los profesionales encuestados disponía de correo electrónico en su puesto de trabajo $(54,2 \%)$ y un $22,7 \%$ lo tenía en casa (Cantalapiedra et al., 2000)

En estos años, se han producido cambios no solo en el oficio de la profesión periodística (Verón y Sabés, 2008; Domingo \& Paterson, 2011; Hermida, 2013; López et al, 2017), sino también en el modo de consumir la información por parte de la audiencia que ha desarrollado nuevas costumbres y dispone de más medios y de diferentes soportes para recibirla (Ortega et al, 2015; Jiménez et al., 2018; Crusafon et al., 2020).

Todas estas modificaciones han hecho que diferentes generaciones de periodistas tengan que convivir y compartir los usos de nuevas aplicaciones y herramientas sociales (Crucianelli, 2013; Castañeda, 2019). Además, multitud de investigaciones revelan el impacto de las redes sociales 
como medios donde la participación de la ciudadanía es fundamental para difundir contenidos periodísticos sobre acontecimientos importantes (Campos Freire, 2008; Mendiguren et al, 2011; Sintes, 2012; Pérez Soler, 2017; Benaissa, 2018; Landeta et al., 2020) y donde han aparecido nuevos participantes como los bots y proyectos audiovisuales y en streaming que cada vez son más sofisticados. El salto de los propios medios a las redes sociales ha modificado algunos aspectos de la profesión periodística y ha propiciado que haya que adaptar continuamente el contenido a los distintos formatos requeridos por los nuevos medios y, asimismo, ha favorecido la creación de nuevas figuras profesionales en el ámbito de la comunicación (Fuentes, 2012; Rodríguez Fernández, 2012; Meso et al, 2015; Ortega, 2017).

En el estudio que se citaba al comienzo de esta investigación, se hablaba de un periodista "hombre, joven, licenciado en Ciencias de la Información..." (Cantalapiedra et al, 2000: 337). Sin embargo, además de la digitalización de la profesión, la incorporación de la mujer a esta carrera es otro de los hechos más relevantes que ha acontecido en estos últimos años (Rivero et al., 2015). La proporción de mujeres periodistas en los medios de comunicación ha aumentado de forma significativa en los últimos tiempos (Ufarte, 2007). Desde 2002 en España, "el porcentaje de mujeres directivas en periódicos de información general y televisiones, públicas y privadas, se ha incrementado exponencialmente" (Rivas de Roca, 2020: 88). Pese a estos datos tan alentadores, la diferencia estructural que existe entre hombres y mujeres en la sociedad (Menéndez, 2017; Gallego, 2019), se manifiesta también en las redacciones de los medios. La discriminación sistemática de las mujeres periodistas opera a varios niveles (De Miguel et al., 2017) y la existencia de diferencias y de un techo de cristal para las mujeres según se avanza en la escala profesional sigue siendo una de las barreras consolidadas en la profesión que habría que extinguir (De Miguel et al., 2019).

Como consecuencia de esta nueva situación, surge la necesidad de realizar un estudio más actual que abarque una visión mucho más amplia, y con necesaria perspectiva de género (Menéndez, 2007), de la labor periodística. Se trata de explorar cómo afecta a los profesionales del País Vasco, y, más concretamente, a los periodistas, hombres y mujeres, centenials y milenials, esta nueva faceta de la comunicación, dominada por el uso de las redes sociales, las recomendaciones de las empresas informativas sobre este uso y los beneficios o riesgos que los periodistas vascos perciben en la utilización de las mismas.

\section{Estado de la cuestión}

La última edición del "Estudio sobre el uso de redes sociales en España" elaborado por The Social Media destaca que en 2020 el 98\% de la población española comprendida entre 16 y 65 años utiliza las redes sociales. Esto supone que 29 millones de personas utilizan algunas de las plataformas sociales más conocidas como pueden ser Facebook, Twitter, Instagram o la red de mensajería Whatsapp. Este estudio hace especial hincapié en la utilización de las diversas redes sociales según el género. De esta manera, es la población femenina la que en un 51\% supera el empleo general de las mismas. Instagram y Facebook son utilizadas mayoritariamente por mujeres, 54\%, mientras que otras redes como Twitter o Linkedin son mayoritariamente masculinas, 64\% y 53\% respectivamente. Además, se pone de relieve que la mujer participa e interactúa más en todas las redes de las que forma parte y tolera mejor la publicidad tanto en Facebook como en Instagram y Snapchat.

Este uso generalizado de las aplicaciones sociales conlleva un cambio en el consumo de los medios (Cortés, 2016). La mayoría de las visitas directas a la página web de los medios de comunicación en España llegan a través de estas redes sociales y comprar a través de estas aplicaciones es cada vez más una realidad, tras el lanzamiento de nuevas tiendas en Facebook e Instagram y otras funciones que ya están desarrolladas para redes sociales como TikTok, Twitch y Pinterest. 
Estas herramientas sociales también han revolucionado la forma de ejercer la profesión y han propiciado cambios en las rutinas periodísticas y en la creación y adaptación de nuevos contenidos a diferentes formatos con diversas características (Rauchfleisch et al., 2017) y en nuevos sistemas de verificación de contenido (Brandtzaeg et al., 2015). Otra de las características de estos espacios sociales es la celeridad, que también ha traído consigo peligros a la hora de elaborar y compartir la información (Bruno, 2011), y dificultades para delimitar la frontera entre la identidad personal y profesional (Caro, 2016; García Borrego et al., 2018).

Hoy en día, el ejercicio profesional implica, ante todo, una revaloración de los principios esenciales del periodismo, pero también una actualización, formación y puesta al día constante. Se precisan competencias técnicas (Tejedor y Cervi, 2017), cada vez más complejas, que son esenciales para el desarrollo de esta profesión (Peñafiel, 2015). Además, es fundamental también, la capacidad de conectar con la audiencia del medio (Marta et al., 2020) y con un público cada vez más joven con el que hay que saber crear comunidades de diálogo y entendimiento (Herrera y Requejo, 2015). Todas estas nuevas circunstancias, no pueden ser vistas sino como una oportunidad para el desarrollo más profundo de los valores anteriormente citados (Sánchez de la Nieta, 2013, Fuente et al., 2017).

Herrero (2014) destaca como punto de inflexión en la adaptación de la profesión a este panorama dos acontecimientos clave como son los movimientos sociales del 11M y del 15M donde las aplicaciones sociales se consolidan y lideran una nueva forma de hacer y distribuir la información. Apunta la autora a las estrategias comunicativas poco claras y al estado incipiente de las orientaciones de los medios sobre el uso de las mismas por parte de los profesionales.

Varona y Sánchez, por su parte, también denuncian la infrautilización de muchas redes sociales como Tuenti o Linkedin por parte de periodistas a favor de otras más utilizadas como Twitter o Facebook. Destacan el desconocimiento de los profesionales y señalan la necesidad de formación para que se puedan utilizar todas las potencialidades de las aplicaciones sociales en las redacciones (Varona, Sánchez, 2016).

Por otro lado, Wu (2019) segrega por edades a periodistas americanos y analiza los usos profesionales de las redes. Sin embargo, no destaca tanto la diferencia de edad como determinante de la distinción, sino los tipos de redes sociales que unos grupos y otros prefieren utilizar. Mientras que periodistas jóvenes usan Twitter, los profesionales de más edad utilizan Facebook y los de edad media recurren indistintamente a Twitter y a Facebook. Destaca Wu la nueva frontera generacional de los 50 años en vez de los 30 confirmando que no existe gran diferencia entre el uso de redes por parte de periodistas jóvenes y de mediana edad. Es significativo que la verdadera desigualdad esté entre el uso de estas aplicaciones por parte de periodistas mayores de 50 años y de jóvenes.

Es interesante esta distinción de franjas generacionales teniendo en cuenta que el cambio promocional ocurrido en esta década ha contribuido notablemente al incremento de esta ruptura generacional. Una brecha que ya se empieza a plantear como desigualdad digital dentro de los públicos conectados en el propio mundo digital (Yamamoto et al., 2017). Este es el paso de la generación milenial a la centenial. Además, la feminización de los estudios universitarios de Periodismo (De Miguel et al., 2019) y la necesidad de incorporación al mundo laboral hace que estas periodistas centenial, nativas digitales y recién salidas de las facultades se integren en medios y compartan gestión y usos de la información. Tendrán, estas periodistas, que lidiar con algunos de los grandes problemas de la profesión como son la desigualdad estructural, el acoso on line y la discriminación, como lo revelan los últimos informes presentados tanto por la Asociación de la 
Prensa de Madrid como por la Plataforma en Defensa de la Libertad de Información en 2020. De ahí que se haga imprescindible la inclusión de la variable de género en esta investigación.

Por otra parte, las diferentes concepciones del término, llevan a definir a la generación centenial, también llamada generación Z (Dimock, 2019), iGen y Digital Natives (Prensky, 2001), Post Millennials o Centenial (Fundeu, 2018) como a las personas que han nacido a partir de 1991 (Jain et al., 2014), a partir de 1994 (Ortega y Vilanova, 2016), a partir de 1995 (McCrindle, 2014 y Bencsik et al, 2016), a partir de 1996 o a partir de 1997 (Duffet, 2017).

Para el presente estudio se tomará como acepción de centenials la ofrecida por McCrindle (2014) y Bencsik et al. (2016) y se considerarán periodistas centenial a las personas nacidas a partir de 1995 y hasta 2009. Se trata de gente joven, recién graduada que se incorpora a las redacciones de los medios y que tendrá que compartir tareas y conocimientos con periodistas ya asentados en sus puestos de trabajo como son los milenials.

Esta generación $\mathrm{Z}$ agrupa a las personas que han nacido con el desarrollo de la World Wide Web, con smartphones y tabletas entre sus manos y con un uso masivo de las redes sociales como seña de identidad. De esta forma, cada vez tienen más oportunidades de participar en multitud de proyectos culturales, sociales y de expresar su creatividad. Estas grandes perspectivas también suponen un reto para esta generación, que deberá saber equilibrar su vida real y "cibernética", así como lidiar con el riesgo de adicción tecnológica y otros peligros relacionados con la privacidad, el acoso y el cibercrimen (Ortega y Villanova, 2016).

La consideración de milenials, también fluctúa desde las personas nacidas a partir de 1977 (Kim et al., 2009), desde 1980 (Bencsik et al.,2016) e incluso después de 1981 y 1982 (Pendergast, 2010). Se tomará para el presente estudio la consideración de milenials a los profesionales nacidos entre 1977 y 1994.

Esta generación, por su parte, ha crecido paralelamente al surgimiento de internet y de las redes sociales. Navegan con fluidez y utilizan reproductores de audio y video digitales a diario; utilizan las imágenes digitales que manipulan y envían; y usan, además, sus ordenadores para crear videos, presentaciones multimedia, música y blogs (García, Portillo y Benito, 2008). Estas personas tienen la necesidad de compartir sus experiencias y de relacionarse de manera activa en las redes sociales. Sin embargo, esta generación es muy heterogénea y hay milenials más actuales que incluso llegan a confundirse con los de las generaciones centenials. (Marín y Simancas, 2019).

\section{Objetivo e hipótesis}

La presente investigación está compuesta por 7 variables generales que nos dan una visión global de la actividad periodística en el País Vasco: percepción sobre la práctica del periodismo, prácticas periodísticas, cambios en la profesión y organización del trabajo, relación de los medios y sus audiencias, uso de redes sociales, impacto de las redes sociales en el trabajo y el género en la profesión del periodismo.

Presentamos los resultados de las encuestas sobre las variables relacionadas específicamente con el uso de las redes sociales y del impacto de las mismas en el trabajo periodístico. El principal objetivo de esta investigación es analizar el empleo que hacen diferentes generaciones de periodistas vascos, generación $\mathrm{Z}$ y milenials, de las principales herramientas de comunicación y de las redes sociales en el ejercicio de su profesión. 
Se analizará si existen diferencias en los criterios y en la utilización de estas plataformas sociales en generaciones consecutivas de periodistas que trabajan en distintos medios de comunicación. Asimismo, se estudiará si existen diferencias de género en el uso de estos medios por parte de los profesionales de la información.

Se parte de las siguientes hipótesis descriptivas:

H1. La diferencia entre generación centenial y milenial se refleja en el uso de las redes sociales en las redacciones de los medios de comunicación vascos. Se asocia el empleo de herramientas como Facebook o Twitter a profesionales de la generación milenial mientras que se relacionan con plataformas como Instagram o Youtube a perfiles más jóvenes de periodistas.

H2. Pese a que el empleo de las redes sociales tanto por parte de hombres y como de mujeres periodistas es un hecho generalizado, siguen existiendo diferencias de género en su uso y en su concepción sobre los beneficios y los riesgos que conllevan.

H3. Existe una infrautilización de las redes sociales como fuentes de información lo que significa que todavía existe desconfianza y/o desconocimiento por parte de los profesionales sobre su uso.

\section{Metodología}

Para la realización de este estudio, se recurrió a la encuesta como técnica de investigación (De Rada, 2012). Un cuestionario es la herramienta que permite plantear un conjunto de preguntas para recoger información estructurada sobre una muestra determinada, empleando el tratamiento cuantitativo y agregado de las respuestas para poder describir a la población a la que pertenecen y poder contrastar estadísticamente relaciones entre medidas de interés (Meneses, 2016). Se confeccionó un cuestionario CAWI (Computer Assisted Web Interview) formado por 26 preguntas cerradas y anónimas que analizó temas como el empleo de las redes sociales en la profesión o los cambios en la organización del trabajo, entre otros. Las preguntas eran, en su mayoría, de opción múltiple de respuesta simple mientras que había 12 items que eran de respuesta múltiple (escala de Likert de 0 a 5 puntos). Asimismo, para la elaboración de la muestra, se contó con la colaboración de la Euskal Kazetarien Elkartea /Asociación Vasca de Periodistas y Kazetarien Euskal Elkargoa / Colegio Vasco de Periodistas. Se trataba de conseguir un patrón lo suficientemente representativo de 500 periodistas que trabajaran en medios de comunicación, con un equilibrio en términos de género $(50 \%$ de hombres y mujeres), territorios históricos (Araba, Bizkaia y Gipuzkoa) y medios de comunicación, procurando que hubiera personas trabajadoras del mayor número posible de medios de comunicación (prensa, radio y televisión).

Según el Instituto Vasco de Estadística, Eustat, en 2020, las personas empleadas en la Comunidad Autónoma del País Vasco en el sector de la Información y Comunicación eran 22.564. Sin embargo, hay que tener en cuenta que este sector incluye también profesiones que no son estrictamente trabajadores de los medios de comunicación. La encuesta realizada para nuestro estudio compuesta por 500 entrevistas daría una margen de error del $4 \%$ con un nivel de confianza del análisis del $95 \%$ por lo que consideramos suficientemente representativa para el análisis.

Para la obtención del listado de rastreo se comenzó por la Guía de la Comunicación Abierta del Gobierno Vasco donde se incluye la relación de las personas responsables de las principales áreas de comunicación en los medios de Euskadi. Posteriormente y utilizando como técnica "bola de nieve" se completó el listado. Para concluir el estudio, se tuvo en cuenta los perfiles de los profesionales que aparecían en las redes sociales de cada medio de comunicación. 
El trabajo de campo se realizó entre el 12 de abril y el 24 de mayo de 2020 y, en total, intervinieron 522 periodistas que ejercen en el País Vasco. La realización de las preguntas del cuestionario anónimo vino dada por parte del equipo investigador pero la realización de las mismas se delegó en la empresa CPS Estudios de Mercado y Opinión que llevó a cabo las encuestas con varias metodologías, como la autoadministrada mediante link online, aunque también se llevaron a cabo telefónicamente, si así lo prefería la persona a encuestar. Se realizó un Pretest para poder analizar la acogida de todos los participantes en el estudio. En todos los casos se notificó que la información obtenida iba a ser utilizada exclusivamente para la investigación y no con fines comerciales. En este caso, no hubo un comité de ética que validara el procedimiento.

El trabajo que se desarrolló fue desde la creación de una base de datos con contactos de periodistas, una programación del cuestionario en la plataforma propia de encuestado online de CPS, contacto y recogida de información, creación de $\mathrm{BD}$ de resultados, grabación, validación y redacción de informes de campo.

Se establecieron cuatro parámetros de edades para el análisis. Se ha considerado como periodistas centenials a personas nacidas entre 1995 y 2009; milenials a las nacidas entre 1977 y 1994; Generación X (nacidas entre 1965 y 1980); y baby boomers (periodistas de más de 60 años). En la presente investigación se muestran exclusivamente los resultados comparativos de centenials y milenials. Para comprobar la validez de constructo de tipo convergente de este estudio se analizaron las correlaciones entre varias variables.

Los resultados que exponemos a continuación recogen las cinco variables específicas del análisis sobre el empleo de redes sociales como son: el uso de las principales herramientas y aplicaciones de mensajería para ejercer el periodismo, las redes sociales utilizadas en el trabajo diario, los recursos audiovisuales y blogs empleados, beneficios en el uso de las redes sociales en el periodismo y riesgos y amenazas derivadas del uso de estas plataformas sociales.

\section{Resultados}

\subsection{Herramientas y aplicaciones de mensajería para ejercer el periodismo}

Prácticamente la totalidad de periodistas vascos, tanto centenials como milenials, utilizan casi siempre o bastantes veces el teléfono $(98,44 \%$ y $97,4 \%$ ) y el correo electrónico $(96,16 \%$ y $98 \%)$ convirtiéndose en las herramientas más empleadas en las redacciones de los medios y, que en el caso de este último, se trata de un canal que está adquiriendo importancia en la vida diaria (Newman, 2020).

Otra aplicación que posibilita dinamizar información de manera rápida y con calidad y que constituye una herramienta de trabajo y un mecanismo ineludible para la interacción con los usuarios es Whatsapp (Giraldo y Cardona, 2018), que además posibilita establecer contactos directos con las audiencias (Palomino-González, 2019). Como se puede apreciar en el gráfico 1, no existen grandes diferencias entre el uso de herramientas de mensajería como Whatsapp por parte de estos targets de edad puesto que en ambos casos se puede hablar también de un uso generalizado en el 94,61\% en el caso de los centenials y en el $91 \%$, en el caso de los milenials.

A pesar de contar con ventajas técnicas (Martín Granados, 2016) e innumerables opciones (Thorsen y Jackson, 2018), y de asegurar privacidad en sus mensajes, a través de chats secretos, mensajes encriptados y canales personalizados para el usuario, el empleo que hacen los profesionales de Telegram es minoritario. Aspira a ser una de las aplicaciones preferidas de los medios de 
comunicación por su utilidad y a establecer nuevas prácticas de producción y difusión periodística (Sánchez y Martos, 2020). Sin embargo, la generación centenial lo usa en el 11\% de los casos (casi siempre o bastantes veces), incrementándose su uso hasta un $23 \%$ en la franja de edad comprendida entre los 27 y los 44 años.

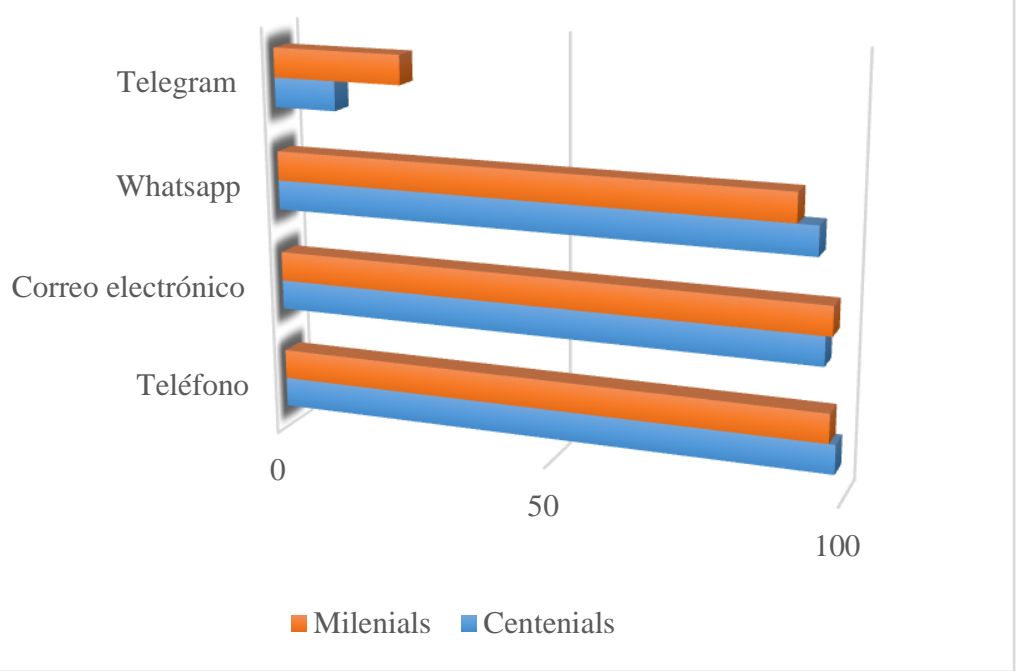

Gráfico 1. Herramientas y aplicaciones de mensajería para el periodismo

Fuente: Elaboración propia

Mientras que en la utilización del teléfono, correo electrónico o Whatsapp no se ven diferencias significativas desagregadas por sexo (tabla 1), Telegram es mayoritariamente femenino entre las centenials y masculino entre la generación milenial, llegando a emplearse tanto ocasionalmente como frecuentemente en el $44 \%$ de los casos.

Tabla 1. Uso del teléfono, correo electrónico y aplicaciones de mensajería desagregado por sexo

\begin{tabular}{|c|c|c|c|c|c|c|c|c|c|c|c|c|}
\hline & \multicolumn{6}{|c|}{-} & \multicolumn{6}{|c|}{ Milenials } \\
\hline & \multicolumn{2}{|l|}{ Nunca } & \multicolumn{2}{|c|}{ Ocasionalmente } & \multicolumn{2}{|c|}{$\begin{array}{l}\text { Casi siempre/ } \\
\text { Bastantes veces }\end{array}$} & \multicolumn{2}{|l|}{ Nunca } & \multicolumn{2}{|c|}{ Ocasionalmente } & \multicolumn{2}{|c|}{$\begin{array}{l}\text { Casi } \quad \text { siempre/ } \\
\text { Bastantes veces }\end{array}$} \\
\hline & $\mathrm{H}$ & M & $\mathrm{H}$ & $\mathrm{M}$ & $\mathrm{H}$ & $\mathrm{M}$ & $\mathrm{H}$ & $\mathrm{M}$ & $\mathrm{H}$ & $\mathrm{M}$ & $\mathrm{H}$ & $\mathrm{M}$ \\
\hline Teléfono & - & - & - & $3,13 \%$ & $100 \%$ & $96,88 \%$ & $1,03 \%$ & - & $3,09 \%$ & - & $94,85 \%$ & $100 \%$ \\
\hline $\begin{array}{l}\text { Correo } \\
\text { electrónico }\end{array}$ & - & - & $4,55 \%$ & $3,13 \%$ & $95,45 \%$ & $96,88 \%$ & - & - & $2,06 \%$ & - & $95,87 \%$ & $100 \%$ \\
\hline Whatsapp & & & $4,55 \%$ & $6,25 \%$ & $95,46 \%$ & $93,76 \%$ & $4,12 \%$ & $1,28 \%$ & $5,15 \%$ & $6,41 \%$ & $89,69 \%$ & $92,3 \%$ \\
\hline Telegram & $72,73 \%$ & $68,75 \%$ & $20,45 \%$ & $15,63 \%$ & $6,82 \%$ & $15,63 \%$ & $55,67 \%$ & $64,47 \%$ & $17,53 \%$ & $15,79 \%$ & $26,8 \%$ & $19,74 \%$ \\
\hline
\end{tabular}

\subsection{Redes sociales utilizadas en el trabajo diario}

En este aparatado se recogen las principales opiniones sobre el uso de las cuatro redes sociales más utilizadas para el ejercicio de la profesión periodística: Facebook, Twitter, Instagram y Linkedin, pese a que algunos autores incluyen Youtube entre ellas (Benaissa, 2018). 
Incluimos en el estudio Facebook como red social, Twitter como red y servicio de microblogging e Instagram como aplicación visual por excelencia con predominio de la imagen y el vídeo. También analizamos Linkedin como red social basada en estrategias de networking para trabajar la red de contactos y generar notoriedad (Alastruey, 2011).

Linkedin es la primera red social, de las analizadas, en aparecer en el panorama digital en 2002 seguida por Facebook en 2004, Twitter en 2005 e Instagram en 2010. Todas ellas se hallan plenamente instaladas en los medios de comunicación del País Vasco (García y Marta-Lazo, 2017).

El cuestionario incorporaba preguntas sobre los principales motivos de la utilización de estas plataformas y de la diferencia entre el uso personal y profesional de las mismas. Se preguntó también sobre si existe algún tipo de recomendación por parte del medio de comunicación sobre su empleo.

Pese a que pueda existir una presión por parte de las empresas periodísticas para que su personal extienda su influencia a internet (Bossio y Sacco, 2017), el 48\% de periodistas reconocen que no existe ningún tipo de exigencia por parte de la empresa informativa sobre el empleo de las redes sociales. Así, el $77 \%$ de los profesionales reconocen que hacen un uso tanto personal como profesional de sus perfiles. Solo las utilizan de forma profesional el 19\% y de forma personal el $10 \%$ de los mismos. A pesar de que el empleo de redes sociales posibilita a los profesionales de la comunicación conseguir reconocimiento, reputación y remuneración (Marauri et al., 2018), no se han apreciado entre los periodistas encuestados colisiones entre el interés por tener y hacer crecer un perfil personal y los posibles daños que se pueda causar a la empresa informativa (Hanusch, 2018).

El 98\% de los participantes reconocen que no hacen un uso diario de sus redes sociales y los usos prioritarios profesionalmente hablando van desde: conseguir ideas para nuevos temas (64\%), pulsar opiniones (44\%), responder preguntas a los usuarios $(31 \%)$, corregir errores (26\%) y compartir informaciones adicionales o informaciones de fondo (25\%).

Varios estudios destacan el empleo de Twitter como herramienta fundamental para el periodismo (Rodríguez y García, 2013; López Meri, 2015; Hernández-Fuentes y Monnier, 2020; Peña et al., 2021). Como se puede comprobar en el gráfico 2, en la presente investigación sobresale igualmente la red de microblogging como la red social más utilizada, casi siempre o bastantes veces, por la generación centenial $(92,76 \%)$ en mayor medida que por la milenial $(82,65 \%)$. Su uso también difiere desde una perspectiva de género (tabla 2) puesto que es utilizado mayoritariamente por mujeres jóvenes $(96,88 \%)$ frente al $88,65 \%$ del uso que hacen los hombres. Entre los milenials no existe tanta diferencia de género en su utilización.

Facebook, con su mayor potencial como fuente de consulta y como canal para llegar a una audiencia situada en una órbita muy alejada de la edición en papel o incluso de la web (García de Torres et al., 2015), es una red empleada en el 31,25\% de los casos, siendo las mujeres periodistas las que hacen un uso más extensivo de la misma, sobre todo en la generación milenial. Las periodistas menores de 30 años usan Facebook casi siempre o bastantes veces en un 37,51\% mientras que los periodistas varones la utilizan en el $25 \%$ de los casos. Sin embargo, el uso ocasional de la misma se incrementa entre los varones y decae entre las mujeres periodistas. 


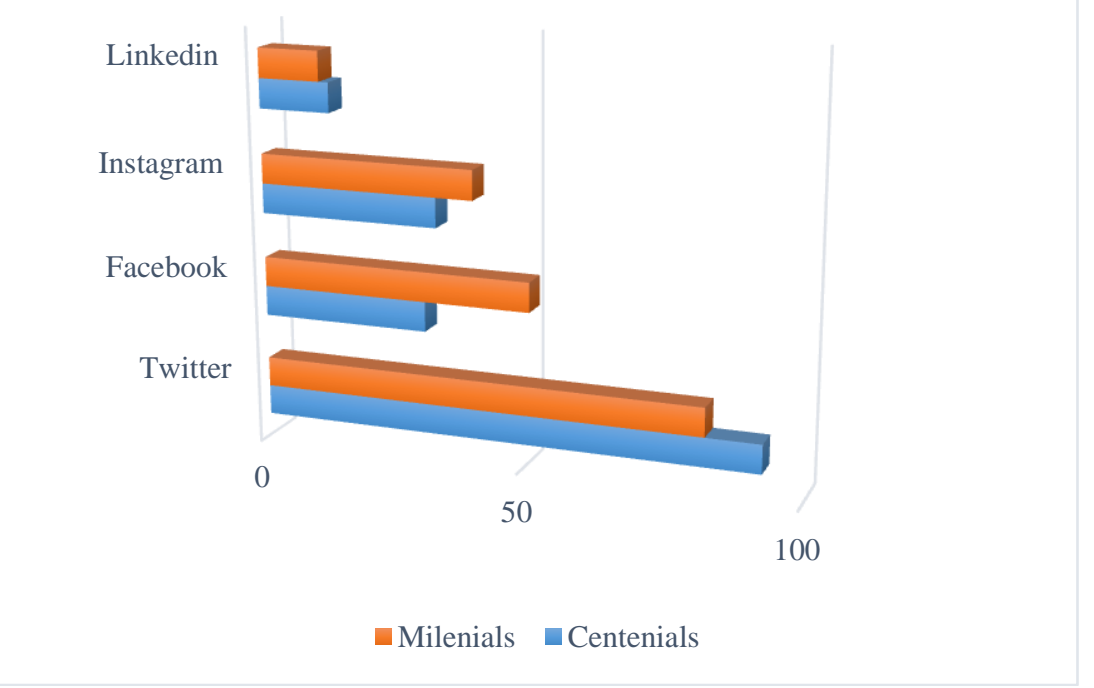

Gráfico 2. Redes sociales más utilizadas en el periodismo

Fuente: Elaboración propia

Instagram, una red que crece en su uso periodístico (Rojas y Panal, 2017), también plantea diferencias en su uso generacional siendo los profesionales centenials los que la utilizan en menor medida $(31,25 \%)$ mientras que los milenials acrecientan su empleo llegando al $40 \%$. Aunque el uso generalizado de esta red por parte de las mujeres tanto centenials como milenials es mayor que la utilización que hacen los hombres (41\% y 33\%), también destaca el dato de que el $40 \%$ de mujeres tanto centenials como milenials no usa nunca Instagram en su tarea periodística.

Por último, Linkedin se convierte en una red relegada para el ejercicio del periodismo, donde su uso se restringe a un $13,5 \%$ en el caso de los centenials que la utilizan casi siempre o bastantes veces, y a un $11,6 \%$ en el caso de los milenials, no existiendo grandes sesgos de género en su análisis. Como justificación de esta infrautilización está la creencia de que es una herramienta exclusivamente para la búsqueda de empleo. También existe un gran desconocimiento de este soporte y de todas las particularidades del mismo que pueden ser usados para la profesión (creación de grupos de discusión, aplicaciones, contactos...).

En general, las personas encuestadas utilizan los medios sociales, pero sin conocer en profundidad las especificidades de los mismos relacionadas con la profesión. Su uso es muy superficial, más relacionado con su uso personal, y no existe una conciencia clara de necesidad de profundizar en estas herramientas.

Según el dossier anual de Digital News Report presentado por la Universidad de Navarra y el informe "Top tendencias Digitales 2021" presentado por la asociación de publicidad, marketing y comunicación digital en España, (IAB Spain, 2021) existen otras plataformas «nicho» en su origen, como TikTok y Twitch, que se han convertido en las protagonistas absolutas del consumo juvenil y continuarán creciendo para llegar a ser claves para los profesionales del periodismo y de la publicidad.

De hecho, la influencia de una red como Tik Tok es cada vez más importante y parece evidente que los profesionales del periodismo se tendrán que adaptar a la lógica de esta plataforma (con su rapidez 
y viralidad) si se quieren dirigir a un target joven de población que consume los medios de distinta manera (Vazquez-Herrero et al., 2020).

Por su parte, la adaptación de contenidos y nuevos formatos a plataformas de streaming como Twitch lleva a reformular la manera en la que se ejerce la profesión. La sensación de disfrute por parte de los usuarios de los medios de comunicación cuando se utiliza Twitch (Wulf et al., 2020) es vista con envidia por parte del periodismo que se ve en la obligación de adaptar contenidos y formatos a este nuevo público consumidor.

En la encuesta de esta investigación se preguntó también sobre el uso de estas nuevas plataformas y, aunque un $65 \%$ de los centenials y un $28 \%$ de los milenials ha reconocido tener perfiles en redes sociales como Tik Tok o Twitch, ninguna de las personas encuestadas hace uso de ellas en el ejercicio del periodismo.

Tabla 2. Uso de redes sociales en el periodismo desagregado por sexo

\begin{tabular}{|c|c|c|c|c|c|c|c|c|c|c|c|c|}
\hline & \multicolumn{6}{|c|}{ Centenials } & \multicolumn{6}{|c|}{ Milenials } \\
\hline & \multicolumn{2}{|l|}{ Nunca } & \multicolumn{2}{|c|}{ Ocasionalmente } & \multicolumn{2}{|c|}{$\begin{array}{l}\text { Casi siempre/ } \\
\text { Bastantes veces }\end{array}$} & \multicolumn{2}{|l|}{ Nunca } & \multicolumn{2}{|c|}{ Ocasionalmente } & \multicolumn{2}{|c|}{$\begin{array}{l}\text { Casi siempre/ } \\
\text { Bastantes veces }\end{array}$} \\
\hline & $\mathrm{H}$ & M & $\mathrm{H}$ & M & $\mathrm{H}$ & $\mathrm{M}$ & $\mathrm{H}$ & $\mathrm{M}$ & $\mathrm{H}$ & M & $\mathrm{H}$ & M \\
\hline Twitter & $2,27 \%$ & - & $9,09 \%$ & $3,38 \%$ & $88,64 \%$ & $96,88 \%$ & $3,09 \%$ & $5,13 \%$ & $11,34 \%$ & $14,10 \%$ & $84,54 \%$ & $80,76 \%$ \\
\hline Facebook & $31,82 \%$ & $34,38 \%$ & $43,18 \%$ & $28,13 \%$ & $25 \%$ & $37,51 \%$ & $17,53 \%$ & $17,95 \%$ & $29,90 \%$ & $30,77 \%$ & $50,52 \%$ & $51,29 \%$ \\
\hline Instagram & $25 \%$ & $40,63 \%$ & $45,45 \%$ & $21,88 \%$ & $29,54 \%$ & $37,5 \%$ & $38,14 \%$ & $41,03 \%$ & $23,71 \%$ & $14,10 \%$ & $36,08 \%$ & $44,87 \%$ \\
\hline Linkedin & $61,36 \%$ & $53,13 \%$ & $27,27 \%$ & $31,25 \%$ & $11,37 \%$ & $15,63 \%$ & $58,76 \%$ & $57,14 \%$ & $29,90 \%$ & $29,87 \%$ & $10,31 \%$ & $12,98 \%$ \\
\hline
\end{tabular}

\subsection{Recursos audiovisuales y blogs}

Teniendo en cuenta que muchos de los profesionales de los medios de comunicación encuestados trabajan en medios audiovisuales o digitales, el uso de recursos como imágenes, vídeos o blogs como elementos de consulta está generalizado. Los medios han abandonado su relación directa con la audiencia (Noguera Vivo, 2016) para, entre otras cuestiones, empezar a diseñar contenidos para otros canales como Youtube (Peer y Ksiazek, 2010) y a impulsar la expansión del periodista con un canal en esa plataforma (Lorenz, 2018), en un deseo por buscar conectar y fidelizar a una audiencia joven, la más presente en esta red (Bernal y Carvajal, 2020). De hecho, para los editores de medios españoles, Youtube es la segunda de las redes sociales que más ha impactado en sus actividades y que más valor puede aportar a sus negocios en el futuro (Campos Freire et al., 2016). 


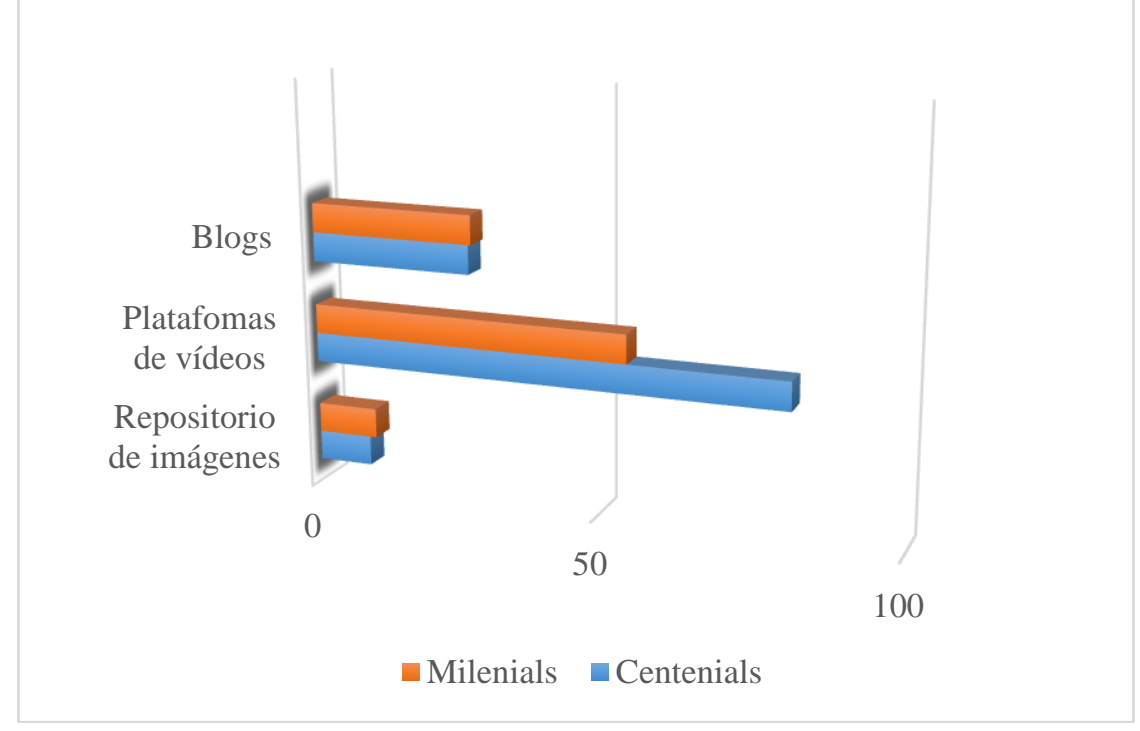

Gráfico 3. Utilización de recursos audiovisuales y blogs

Fuente: Elaboración propia

Pese a ello, el uso de repositorios de imágenes como Flickr o Google Imágenes para el trabajo periodístico tanto por parte de los centenials como de los milenials es muy residual no llegando al $10 \%$ en ningún caso. Algo parecido pasa con Youtube. Aunque el vídeo se ha convertido en una prioridad para medios de comunicación y plataformas sociales como Facebook, en España son escasos los periodistas que toman la iniciativa de adoptar un rol activo en la principal plataforma de difusión audiovisual (Blanco y Palomo, 2019).

En la utilización de plataformas de alojamiento de vídeos como Youtube o Vimeo, tampoco existen grandes diferencias entre el uso por parte de centenials $(53,95 \%)$ o el empleo por parte de milenials $(55,36 \%)$. Los profesionales de menos de 30 años utilizan más estas plataformas audiovisuales que sus compañeras, que en el $34 \%$ de los casos no llegan a utilizar nunca estos recursos.

Pese a que los blogs son uno de los recursos más utilizados para la creación de una marca personal y una reputación on line (Singer, 2015; Marauri et al., 2018), la consulta de bitácoras o blogs por parte de los profesionales vascos tampoco está generalizada. Su uso se restringe al $27,84 \%$ de los casos en centenials y al $28,26 \%$ en el caso en milenials. Destaca el mayor uso por parte de las mujeres periodistas que, casi siempre o bastantes veces, utilizan más estos recursos tanto en el caso de las centenials (37,5 frente al $18 \%$ de hombres) y en el caso de las milenials, (44,8\% frente al $11,65 \%$ de hombres). 
RLCS, Revista Latina de Comunicación Social, 79, 91-116

[Investigación] DOI: 10.4185/RLCS-2021-1525| ISSN 1138-5820| Año 2021

Tabla 3. Uso de recursos audiovisuales y blogs desagregado por sexo

\begin{tabular}{|c|c|c|c|c|c|c|c|c|c|c|c|c|}
\hline & \multicolumn{6}{|c|}{ Centenials } & \multicolumn{6}{|c|}{ Milenials } \\
\hline & \multicolumn{2}{|l|}{ Nunca } & \multicolumn{2}{|c|}{ Ocasionalmente } & \multicolumn{2}{|c|}{$\begin{array}{l}\text { Casi siempre/ } \\
\text { Bastantes veces }\end{array}$} & \multicolumn{2}{|l|}{ Nunca } & \multicolumn{2}{|c|}{ Ocasionalmente } & \multicolumn{2}{|c|}{$\begin{array}{l}\text { Casi siempre/ } \\
\text { Bastantes veces }\end{array}$} \\
\hline & $\mathrm{H}$ & $\mathrm{M}$ & $\mathrm{H}$ & $\mathrm{M}$ & $\mathrm{H}$ & $\mathrm{M}$ & $\mathrm{H}$ & $\mathrm{M}$ & $\mathrm{H}$ & $\mathrm{M}$ & $\mathrm{H}$ & $\mathrm{M}$ \\
\hline $\begin{array}{l}\text { Repositorios } \\
\text { imágenes }\end{array}$ & $84,09 \%$ & $84,38 \%$ & $6,82 \%$ & $6,25 \%$ & $9,1 \%$ & $9,38 \%$ & $67,01 \%$ & $66,30 \%$ & $26,80 \%$ & $24,10 \%$ & $5,15 \%$ & $10.39 \%$ \\
\hline $\begin{array}{l}\text { Plataformas } \\
\text { de vídeo }\end{array}$ & $13,64 \%$ & $34,38 \%$ & $31,82 \%$ & $28,13 \%$ & $44,54 \%$ & $37,51 \%$ & $16,49 \%$ & $15,38 \%$ & $27,84 \%$ & $30,77 \%$ & $55,67 \%$ & $53,84 \%$ \\
\hline Blogs & $31,82 \%$ & $40,63 \%$ & $50 \%$ & $21,88 \%$ & $18,18 \%$ & $37,5 \%$ & $43.93 \%$ & $18,64 \%$ & $43,36 \%$ & $38,72 \%$ & $11,65 \%$ & $44,87 \%$ \\
\hline
\end{tabular}

\subsection{Beneficios del uso de redes sociales en el periodismo}

En el cuestionario se han planteado los beneficios que puede tener el uso de los medios sociales en la tarea periodística. Se consideran cinco premisas como son: encontrar nuevas historias; promocionar la información; informar con mayor rapidez; mejorar la relación con la audiencia; y aumentar la credibilidad.

Tanto centenials como milenials están en un $80 \%$ muy o bastante de acuerdo con que las plataformas sociales ayudan a encontrar nuevas historias, promocionar la información que se publica y a que ésta se distribuya con mayor rapidez. Ambos targets de edad también comparten la opinión de que se mejora la relación con la audiencia con el uso de estas herramientas en un $70 \%$, los centenials, (muy/bastante de acuerdo) y en un 73\% la generación milenial (muy/bastante de acuerdo).

Sin embargo, es bajo el porcentaje (30\% muy/bastante de acuerdo) tanto de centenials como de milenials que está de acuerdo con que el uso de los medios sociales ayude a aumentar la credibilidad a los periodistas. En todos los casos, los centenials son los que han apoyado con más énfasis estas afirmaciones. En el caso de las periodistas milenials, son ellas las que apoyan en mayor medida todas estas afirmaciones. 
RLCS, Revista Latina de Comunicación Social, 79, 91-116

[Investigación] DOI: 10.4185/RLCS-2021-1525| ISSN 1138-5820| Año 2021

Tabla 4. Beneficios del uso de redes sociales según periodistas desagregados por sexo

\begin{tabular}{|c|c|c|c|c|c|c|c|c|c|c|c|c|}
\hline & \multicolumn{6}{|c|}{ Centenials } & \multicolumn{6}{|c|}{ Milenials } \\
\hline & \multicolumn{2}{|l|}{ Nunca } & \multicolumn{2}{|c|}{ Ocasionalmente } & \multicolumn{2}{|c|}{$\begin{array}{l}\text { Casi siempre/ } \\
\text { Bastantes veces }\end{array}$} & \multicolumn{2}{|l|}{ Nunca } & \multicolumn{2}{|c|}{ Ocasionalmente } & \multicolumn{2}{|c|}{$\begin{array}{l}\text { Casi siempre } \\
\text { Bastantes veces }\end{array}$} \\
\hline & $\mathrm{H}$ & $\mathrm{M}$ & $\mathrm{H}$ & $\mathrm{M}$ & $\mathrm{H}$ & $\bar{M}$ & $\mathrm{H}$ & $\bar{M}$ & $\mathrm{H}$ & $\mathrm{M}$ & $\mathrm{H}$ & $\bar{M}$ \\
\hline $\begin{array}{l}\text { Promocionar } \\
\text { información }\end{array}$ & $2,27 \%$ & $6,45 \%$ & $11,36 \%$ & $9,68 \%$ & $79,55 \%$ & $74,19 \%$ & $2,1 \%$ & $6,76 \%$ & $42,11 \%$ & $12,16 \%$ & $29,47 \%$ & $79,73 \%$ \\
\hline $\begin{array}{l}\text { Mejorar la } \\
\text { relación con } \\
\text { la audiencia }\end{array}$ & $2,27 \%$ & $9,68 \%$ & $18,18 \%$ & $12,90 \%$ & $77,27 \%$ & $61,29 \%$ & $4,21 \%$ & $4,05 \%$ & $20 \%$ & $18,92 \%$ & $55,67 \%$ & $74,33 \%$ \\
\hline $\begin{array}{l}\text { Aumentar } \\
\text { credibilidad } \\
\text { periodistas }\end{array}$ & $15,91 \%$ & $35,48 \%$ & $38,64 \%$ & $12,90 \%$ & $31,82 \%$ & $29,03 \%$ & $21,05 \%$ & $28,38 \%$ & $32,11 \%$ & $29,73 \%$ & $29,47 \%$ & $29,73 \%$ \\
\hline $\begin{array}{l}\text { Encontrar } \\
\text { nuevas } \\
\text { historias }\end{array}$ & - & - & $13,64 \%$ & $22,58 \%$ & $86,36 \%$ & $77,42 \%$ & $2,11 \%$ & $2,70 \%$ & $29,47 \%$ & $10,81 \%$ & $67,37 \%$ & $86,48 \%$ \\
\hline $\begin{array}{l}\text { Informar con } \\
\text { mayor } \\
\text { rapidez }\end{array}$ & $2,27 \%$ & $3,23 \%$ & $9,09 \%$ & $9,68 \%$ & $88,64 \%$ & $83,87 \%$ & $4,21 \%$ & $6,76 \%$ & $11,58 \%$ & $9,46 \%$ & $82,1 \%$ & $81,08 \%$ \\
\hline
\end{tabular}

\subsection{Riesgos y amenazas del uso de redes sociales en el periodismo}

A la hora de realizar la encuesta sobre los posibles riesgos o amenazas que tiene el uso de las redes sociales en la tarea periodística (Fajardo, 2018), se han considerado las cuatro premisas más extendidas en el imaginario social sobre la profesión periodística: suponen el fin de los valores tradicionales del periodismo (Enguix, 2019), amenazan la calidad del mismo (Yepes, 2021; Monpart et al., 2015), exponen al periodista más ante el público (Suárez y Álvarez, 2016) y sacrifican la precisión por la velocidad (Martín Algarra et al., 2010).

En lo que se refiere al riesgo que se corre de pérdida de valores del periodismo con la llegada de las aplicaciones sociales, centenials y milenials están de acuerdo con esta afirmación en un 39\% (muy/bastante de acuerdo) y en un $40,89 \%$ los milenials (muy/bastante de acuerdo). Tanto las periodistas centenials como milenials son las que están casi siempre o bastantes veces de acuerdo con esta premisa ( $42 \%$ y $46 \%$ respectivamente). Esto contradice investigaciones como la de De Miguel (2019), donde se subraya que las mujeres periodistas no perciben tanto como los hombres la decadencia cualitativa y deontológica del periodismo actual.

La premisa de que las redes sociales son una amenaza para el periodismo es compartida en porcentajes similares tanto por centenials ( $58 \%$ están muy o bastante de acuerdo) como por milenials $(59,65 \%$ están muy o bastante de acuerdo). Sin embargo, son las mujeres las que están casi siempre o bastantes veces de acuerdo con esta amenaza.

El hecho de ver al profesional más expuesto al público con el uso de las redes sociales es corroborado tanto por centenials (64,73\%, muy/bastante de acuerdo) como por milenials $(60,62 \%$, muy/bastante de acuerdo).

El $80 \%$ tanto de centenials como de milenials están muy o bastante de acuerdo con la idea de que con el uso de las plataformas sociales se ha sacrificado la precisión periodística por la velocidad a la hora de publicar contenidos. 
RLCS, Revista Latina de Comunicación Social, 79, 91-116

[Investigación] DOI: 10.4185/RLCS-2021-1525| ISSN 1138-5820| Año 2021

Tabla 5. Riesgos y amenazas del uso de redes sociales desagregadas por sexo

\begin{tabular}{|c|c|c|c|c|c|c|c|c|c|c|c|c|}
\hline & \multicolumn{6}{|c|}{ Centenials } & \multicolumn{6}{|c|}{ Milenials } \\
\hline & \multicolumn{2}{|l|}{ Nunca } & \multicolumn{2}{|c|}{ Ocasionalmente } & \multicolumn{2}{|c|}{$\begin{array}{l}\text { Casi siempre/ } \\
\text { Bastantes veces }\end{array}$} & \multicolumn{2}{|l|}{ Nunca } & \multicolumn{2}{|c|}{ Ocasionalmente } & \multicolumn{2}{|c|}{$\begin{array}{l}\text { Casi siempre/ } \\
\text { Bastantes veces }\end{array}$} \\
\hline & $\mathrm{H}$ & M & $\mathrm{H}$ & M & $\mathrm{H}$ & $\mathrm{M}$ & $\mathrm{H}$ & M & $\mathrm{H}$ & M & $\mathrm{H}$ & M \\
\hline $\begin{array}{l}\text { Acabar } \\
\text { valores } \\
\text { tradicionales } \\
\text { periodismo } \\
\end{array}$ & $36,36 \%$ & $37,48 \%$ & $27,27 \%$ & $20,35 \%$ & $36,54 \%$ & $41,94 \%$ & $29,47 \%$ & $22,97 \%$ & $31,58 \%$ & $28,38 \%$ & $35,78 \%$ & $45,94 \%$ \\
\hline $\begin{array}{l}\text { Amenaza } \\
\text { calidad del } \\
\text { periodismo }\end{array}$ & $13,64 \%$ & $12,90 \%$ & $29,55 \%$ & $25,82 \%$ & $54,55 \%$ & $61,29 \%$ & $17,89 \%$ & $9,46 \%$ & $25,26 \%$ & $21,62 \%$ & $53,68 \%$ & $67,57 \%$ \\
\hline $\begin{array}{l}\text { El periodista } \\
\text { está más } \\
\text { expuesto al } \\
\text { público } \\
\end{array}$ & $9,09 \%$ & $16,13 \%$ & $20,45 \%$ & $22,58 \%$ & $68,18 \%$ & $61,29 \%$ & $11,58 \%$ & $8,11 \%$ & $20 \%$ & $22,97 \%$ & $65,26 \%$ & $67,57 \%$ \\
\hline $\begin{array}{l}\text { Sacrificar } \\
\text { precisión por } \\
\text { velocidad }\end{array}$ & $2,27 \%$ & $6,45 \%$ & $13,64 \%$ & $19,35 \%$ & $81,82 \%$ & $74,2 \%$ & $4,21 \%$ & $4 \%$ & $17,89 \%$ & $14,86 \%$ & $75,79 \%$ & $82,43 \%$ \\
\hline
\end{tabular}

La opinión de que estas aplicaciones sociales nunca acabarán con los valores tradicionales del periodismo es compartida por el 55\% de centenials, mientras que, en menor medida, el $41 \%$ de milenials sopesa la misma afirmación.

En general, son las periodistas, tanto centenials como milenials, las que consideran en mayor medida (casi siempre o bastantes veces) a las redes sociales como una amenaza para la calidad del periodismo $(67,43 \%)$ y como destructoras de los valores tradicionales del mismo (44\%).

Según el estudio "Mujeres Periodistas en España 2020" de la Plataforma en Defensa de la Libertad de Expresión, las mujeres periodistas sufren de forma más agresiva el acoso on line e intentan humillarlas en la parte profesional y también en la personal. Ellas tienen que tomar medidas de protección silenciando o bloqueando a usuarios, lo que puede justificar el rechazo a estas plataformas para ejercer su trabajo con calidad y libertad.

\section{Discusión y conclusiones}

El principal objetivo de esta investigación era analizar el empleo que hacen diferentes generaciones de periodistas vascos, generación $\mathrm{Z}$ y milenials, de las principales herramientas de comunicación y de las redes sociales en el ejercicio de su profesión.

Se puede concluir señalando que no se han encontrado grandes diferencias en el empleo de estas aplicaciones sociales por parte de periodistas de dos generaciones como son las centenials y los milenials. Wu (2019) también llega a hallazgos similares entre los periodistas americanos. En general, los resultados indican que el uso de los perfiles digitales está muy generalizado entre las redacciones de los medios de comunicación en el País Vasco. No se puede asociar el uso de redes más actuales a generaciones centenials ni aplicaciones sociales pioneras como Facebook a generaciones milenials porque tanto unas como otras hacen uso de estas herramientas. No se aprecia que exista un sesgo generacional en el uso de redes sociales asociado a las mismas. Facebook e Instagram son utilizadas mayoritariamente por periodistas milenials, mientras que Twitter lo usan periodistas centenials. Tanto en unos casos como en otros se prioriza su gusto o sus intereses periodísticos y no generacionales. Por todo esto, no podemos confirmar nuestra hipótesis de partida. 
Otro de los objetivos era investigar si existen diferencias en los criterios y en la utilización de estas plataformas sociales en generaciones consecutivas de periodistas que trabajan en distintos medios de comunicación. Hemos visto que se sigue recurriendo mayoritariamente, tanto hombres como mujeres, a la utilización de las herramientas clásicas para ejercer la profesión como son el teléfono, el correo electrónico y últimamente, la aplicación de mensajería Whatsapp, reconocida por muchos autores como una herramienta de uso periodístico (Reid, 2016). El empleo del correo electrónico es mayoritario tanto entre la generación centenial, 96\%, como entre la milenial, 98\%. En el manejo de Whatsapp existe alguna diferencia, predominando su uso entre centenials, $95 \%$, más que entre milenials, 90\%. Sin embargo, la red de mensajería Telegram o Linkedin son dos de los recursos menos utilizados por los profesionales siendo el desconocimiento de los mismos la justificación de su infrautilización. Sería necesaria, por parte de los medios, una estrategia clara en redes donde el periodista aporte un verdadero valor a la información con un claro dominio de los lenguajes narrativos y de las rutinas profesionales de verificación (Sánchez de la Nieta y Fuente, 2020).

La intención de este estudio también era analizar si existen diferencias de género en el uso de estos medios por parte de los profesionales de la información. Estas líneas nos llevan a confirmar nuestra segunda hipótesis porque sí existen claras diferencias de género en el uso de las redes sociales. Twitter, seguida de Facebook o Instagram son las que predominan en las redacciones y son utilizadas mayoritariamente por mujeres tanto centenials como milenials. Predomina Twitter entre las periodistas centenials, Facebook en las milenials e Instagram tanto en las periodistas centenials como milenials. También en el uso de bancos audiovisuales y de imágenes existen diferencias de uso según el género, predominando el empleo de estos recursos por parte de los profesionales de los medios. Sin embargo, la consulta de blogs como fuente de información es realizada preferentemente por mujeres periodistas.

El hecho de que las mujeres lideren el uso de estos sistemas sociales no justifica por sí solo el fin de la invisibilidad, el uso del lenguaje no sexista, la incorporación de la mujer como fuente de información y protagonismo, la inclusión de temas tradicionalmente invisibles, la detección de imágenes o contenidos sexistas, la atención a problemáticas sociales que existen en función del género y la exclusión de temáticas que perpetúan los estereotipos de género. Dependerá del grado de compromiso de estas mujeres periodistas, de los hombres periodistas y de los propios medios acabar con las desigualdades.

Las periodistas también son las que ven más amenazada su profesión con la presencia de estas redes sociales. Tanto las profesionales de una generación como las de otra ven desafiados los valores tradicionales del periodismo y creen que las redes sociales no favorecen la credibilidad y reputación de la profesión periodística. La brecha de género es importante en ese aspecto donde las periodistas se muestran más expuestas en redes y su contenido más trivializado y cuestionado como lo pone de manifiesto el estudio realizado por la asociación Closingap en 2019 sobre la disparidad de usos en estos medios sociales. Múltiples investigaciones avisan también del acoso y misoginia que sufren las mujeres periodistas en las redes sociales (Mantilla, 2013; Rego, 2018; Albenga y Biscarrat, 2021)

La tercera hipótesis se formulaba en torno a la infrautilización de estos elementos por desconfianza o por desconocimiento y ambos escenarios quedan confirmados. Se ha comprobado que las redes les ayudan principalmente a estar al tanto de las noticias de última hora y realizar un seguimiento de lo que están contando el resto de medios. La mayoría también utiliza las redes para encontrar ideas y enfoques diferentes y relacionados con los temas en los que están trabajando. Estos resultados indican que los periodistas recurren a estas herramientas especialmente para recopilar información y no tanto como fuente periodística (Varona, Sánchez, 2016), para entrevistar a fuentes o verificar información. 
Hay herramientas sociales que son infrautilizadas por desconocimiento como Linkedin, Telegram o plataformas audiovisuales específicas. También, hemos advertido poca formación en determinadas particularidades específicas dentro de las redes sociales relacionadas con el periodismo (listas en Twitter, búsquedas avanzadas, estadísticas en redes...) que permitirían un mayor dominio y menos recelos en el ejercicio de la profesión. Sería aconsejable la impartición de seminarios muy especializados y dirigidos concretamente al uso periodístico de estas herramientas.

Las redes sociales han cambiado el ejercicio del periodismo y la mayoría de las personas que trabajan en el País vasco creen que han tenido un impacto positivo en su labor informativa. La mayoría destaca aspectos como que les han permitido conectar mejor con sus audiencias, promocionar mejor su trabajo y ser más rápidos en contar historias. A pesar de esto, el estudio también detecta que hay informadores que todavía consideran las redes sociales como una amenaza y desconfían claramente de ellas. De hecho, una de las preocupaciones más comunes está relacionada con la velocidad y es que las redes sociales les llevan a sacrificar la precisión por la celeridad. El hecho de que periodistas hagan un uso de las redes sociales tanto personal como profesional puede estar relacionado con este aspecto. La pérdida de credibilidad es otra de las inquietudes que lleva a desconfiar de estas herramientas a pesar de que llevan tiempo instauradas en las redacciones de los medios y son un instrumento más de su trabajo diario.

Es importante trabajar en estas deficiencias puesto que la juventud se esfuerza por encontrar noticias procedentes de fuentes fiables y basadas en hechos objetivos (Alberto, 2018) y según el informe del Foro Económico Mundial de 2017, es cuidadosa con la información que comparte en Internet y trata de difundir información fiable e intenta frenar la difusión cada vez mayor de las llamadas fake news.

Queda por ver si los intereses periodísticos y de los propios profesionales se adecuan y cómo a las nuevas narrativas de redes sociales como Tik Tok (Alonso-López et. al, 2021) o Twitch (Gutierrez Lozano y Cuartero, 2020), donde está un público más joven y con otro tipo de inquietudes. Ya hemos señalado en este estudio que un $65 \%$ de la generación centenial y un $28 \%$ de la milenial encuestada ha reconocido tener perfiles en estas dos nuevas plataformas. Sin embargo, ninguna hace un uso profesional de ellas y habrá que canalizar y gestionar el contenido de los medios vascos a estas nuevas aplicaciones. También queda por ver cómo los medios luchan contra el alto nivel de desinformación que existe en este tipo de nuevos recursos sociales.

\section{Bibliografía}

Alastruey, R. (2011). El networking. Barcelona, UOC

Albenga, V. y Biscarrat, L. (2021). Aproximaciones feministas de la misoginia en redes sociales: una perspectiva francesa. Investigaciones feministas 12(1), pp. 57-66. https://doi.org/10.5209/infe.69088

Alberto Notario, C. (2018). La generación del Milenio y su papel en el futuro de la inteligencia y la seguridad. En Nota de Futuro 1/2018. http://intranet.bibliotecasgc.bage.es/intranet-tmpl/prog/ local_repository/documents/documents/20576_21824.pdf

Alonso, López, N.; Sidorenko, Bautista, P. y Giacomelli, F. (2021). Beyond challenges and viral dance moves: TikTok as a vehicle for disinformation and fact-checking in Spain, Portugal, Brazil, 
and the USA. Anàlisi: Quaderns de Comunicació $i$ Cultura, 64, 65-84. https://doi.org/10.5565/rev/analisi.3411

Benaissa Pedriza, S. (2018). Las redes sociales como fuente de información periodística en la prensa digital española (El País, El Mundo, La Vanguardia y ABC). index.comunicación, 8(3), 13-42

Bencsik, A., Horváth-Csikós, G., y Juhász, T. (2016). Y and Z Generations at workplaces. Journal of Competitiveness, 8(3), 90-106

Bernal, L., y Carvajal, M. (2020). Presencia, formatos y estrategia de producción de vídeos en YouTube: análisis de caso del diario 'El País'. Estudios sobre el Mensaje Periodístico, 26(1), 2535. https://doi.org/10.5209/esmp.67283

Blanco, S., y Palomo, B. (2019). Desencuentro de los periodistas con Youtube. El profesional de la información, 28(4). https://doi.org/10.3145/epi.2019.jul.11

Bossio, Diana and Sacco, Vittoria (2017). From 'selfies' to breaking tweets. Journalism practice, v. 11, n. 5, pp. 527-543. https://doi.org/10.1080/17512786.2016.117531

Brandtzaeg, P. B., Lüders, M., Spangenberg, J., Rath-Wiggins, L. and Følstad, A. (2015). Emerging journalistic verification practices concerning social media. Journalism Practice, 10(3), 323-342. https://doi.org/10.1080/17512786.2015.1020331

Bruno, N. (2011). Tweet First, Verify Later? How Real-Time Information Is Changing the Coverage of Worldwide Crisis Events. Oxford: Reuters Institute for the Study of Journalism

Campos Freire, F. (2008) Las redes sociales trastocan los modelos de los medios de comunicación tradicionales. Revista Latina de Comunicación Social, 63, 277-286. 10.4185/RLCS-63-2008-767287-293

Campos Freire, F., Rúas-Araujo, J., López, X., y Martínez Fernández, V.A. (2016). Impacto de las redes sociales en el periodismo. El Profesional de la Información, 25(3), 449-457. https://doi.org/10.3145/epi.2016.may.15

Cantalapiedra, González, M. J.; Coca, García, C. y Bezunartea, Valencia, O. (2000). La situación profesional y laboral de los periodistas vascos. ZER: Revista de Estudios de Comunicación, 5(9). https://www.ehu.eus/ojs/index.php/Zer/article/view/17441

Caro Castaño, L. (2016) El discurso de la autopromoción y la autenticidad en las redes sociales: la marca personal y la microcelebridad en Área Abierta. Revista de comunicación audiovisual publicitaria 17 (3), 395-411. http://dx.doi.org/10.5209/ARAB.52438

Castañeda, M. C. (2019). La capacitación en el uso de las herramientas digitales en la práctica periodística. Sintaxis, (2), 47-60

Closingap (2019). Brecha digital de género. Informe 2019. https://closingap.com/actividad/brechadigital/ 
Cortés, Campos, R. (2016). Consumo de medios noticiosos en redes sociales virtuales (RSV) entre estudiantes universitarios. Razón $\quad Y \quad$ Palabra, 20(2_93), 483-496 https://www.revistarazonypalabra.org/index.php/ryp/article/view/31

Crucianelli, S. (2013). Herramientas digitales para periodistas. University of Texas. Knight Center for Journalism in the Americas.

Crusafon, C., Saavedra, C. G. y Murciano, M. (2020). Las redes sociales y las aplicaciones móviles en las estrategias de transformación digital de los medios de servicio público europeos. Comunicació: Revista de Recerca $i \quad$ d'Anàlisi, $\quad 37(2), \quad 33-54$. https://doi.org/10.2436/20.3008.01.195

De Miguel, Pascual, Hanitzch, T., Parratt, S. (2017). Mujeres periodistas en España: análisis de las características sociodemográficas y de la brecha de género. El Profesional de la Información, 26, pp 497-506

De Miguel, Pascual, S Parratt, Fernández, Berganza and Conde, R. (2019). The perception of women journalists about their job. The gender variable in professional culture. Revista Latina de

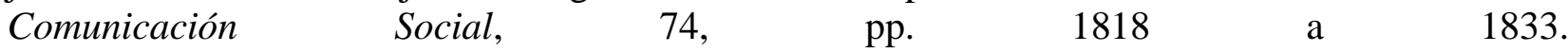
http://www.revistalatinacs.org/074paper/1318/01en.html

De Rada, V. D. (2012). Ventajas e inconvenientes de la encuesta por Internet. Papers: revista de sociologia, 97(1), 193-223 http://dx.doi.org/10.5565/rev/papers/v97n1.71

Dimock, M. (2019). Defining generations: Where Millennials end and Generation Z begins. Pew Research Center. PRC. https://www.pewresearch.org/fact-tank/2019/01/17/where-millennialsend-and-generation-z-begins/

Domingo, D., and Paterson, C.A. (Eds.) (2011). Making Online News: Newsroom Ethnographies in the Second Decade of Internet Journalism. New York: Peter Lang.

Duffett, R. G. (2017). Influence of social media marketing communications on young consumers' attitudes. Young Consumers, 18(1), 19-39. Duffett, R. G., \& Wakeham Dr, M. (2016). Social media marketing communications effect

Enguix, S. (2019). Diez años de redes sociales y periodismo: riesgos y retos en el ecosistema informativo del s. XXI. Revista Dígitos, (5), 164-183

Fajardo Pascagaza, E. (2018). Las redes sociales como herramienta de apoyo a la labor periodística, Sphera Publica, 1 (18), 104-119

Foro Económico Mundial. (2017). Global Shapers Annual Survey 2017. Sharpers Survey 2017: http://www.shaperssurvey2017.org

Fuente, C., Sánchez de la Nieta, M., Monfort, A. (2017). Independencia de los medios informativos, independencia de los periodistas, independencia de las redacciones. En BOIX PALOP, Andrés; MARTÍNEZ OTERO, Juan María and MONTIEL ROIG, Gonzalo. Regulación y control sobre contenidos audiovisuales en España. Pamplona: Aranzadi, 2017, pp.385-406. 
Fuentes, M. (2012). La figura del community manager. In: MARTÍNEZPRIEGO, C. (coord.): Quiero ser community manager. ESIC, Madrid, pp. 97109.

Fundeu (2018). https://www.fundeu.es/consulta/centenial/

Gallego, J. (2019). Morir de éxito. El feminismo en la encrucijada. Paradigma, 22, pp 76-81

García, M., Marta-Lazo, C. (2017). Análisis de Twitter como fuente, recurso de interacción y medio de difusión para los periodistas vascos. Zer, vol 22, n42, pp 73-95 https://doi.org/10.1387/zer.17833

Garcia, F., Portillo, J., Benito, M. (2008). Nativos digitales y modelos de aprendizaje. IV Simposio Pluridisciplinar sobre Diseño, Evaluación y Desarrollo de Contenidos Educativos Reutilizables.

García-Borrego, M., Batlle, P. F., y Rojano, F. J. P. (2018). Límites en el uso profesional de las redes sociales: el perfil de los futuros periodistas. Revista Ibérica de Sistemas e Tecnologias de Informação, (E16), 94-107

García-de-Torres, E., Yezers'Ka, L., Rost, A., Calderín, M., Edo, C., Rojano, M., Said, E., Jerónimo, P., Arcila, C., Serrano, A., Badillo, J., \& Corredoira, L. (2015). Uso de Twitter y Facebook por los medios iberoamericanos. El profesional de la información, 20(6), 611-620. https://doi.org/10.3145/epi.2011.nov.02

Giraldo, C., y Cardona, F.A. (2018). La influencia del Whatsapp en emisoras de radio analógicas. Anagramas Rumbos y Sentidos de la Comunicación, 16 (32), 111-127. https://doi.org/10.22395/angr.v16n32a7

Gutierrez, Lozano, J., Cuartero, A. (2020). El auge de Twitch: nuevas ofertas audiovisuales y cambios del consumo televisivo entre la audiencia juvenil. Ämbitos Revista Internacional de Comunicación, 50, 159-175

Hanusch, F. (2018). Political journalists corporate and personal identities on Twitter profile pages: A comparative analysis in four Westminster democracies. New Media \& Society, 20(4), 1488-1505. https://doi.org/10.1177/1461444817698479

Hermida, A. (2013). \#Journalism: Reconfiguring Journalism Research about Twitter, on Tweet at a Time. Digital Journalism, 1(3), 295-313. https://doi.org/10.1080/21670811.2013.808456

Hernández-Fuentes, A., \& Monnier, A. (2020). Twitter as a Source of Information? Practices of Journalists Working for the French National Press. Journalism Practice, 1-18. https://doi.org/10.1080/17512786.2020.1824585

Herrera, S. y Requejo, J. L. (2015). Crear comunidad. La gran asignatura pendiente para los diarios en Twitter. Telos: Cuadernos de comunicación e innovación, 100, 108-119 https://telos.fundaciontelefonica.com/revista/

Herrero Curiel, E. (2014). Del 11M al 15 M. Periodistas y redes sociales en España. Uoc, Barcelona

IAB Spain Estudio anual de redes sociales 2020. . https://iabspain.es/presentacion-estudio-redessociales-2020/ 
IAB Spain Top Tendencias digitales 2021. https://iabspain.es/etiqueta/top-tendencias-digitales/

Jain, V., Vatsa, R.,y Jagani, K. (2014). Exploring generation Z's purchase behavior towards luxury apparel: A conceptual framework. Romanian Journal of Marketing, 2, 18.

Jiménez, A. G., Viñes, V. T. y Ruiz, Y. P. (2018). Consumo mediático de adolescentes y jóvenes. Noticias, contenidos audiovisuales y medición de audiencias. ICONO 14, Revista de comunicación y tecnologías emergentes, 16(1), 22-46

Kim, H., Knight, D. K., and Crutsinger, C. (2009). Generation Y employees' retail work experience: The mediating effect of job characteristics. Journal of Business Research, 62(5), 548-556.

Landeta, Bejarano, Z., Salamea, Limones, V., Montecé, Mosquera, F. (2020). Redes sociales y periodismo ciudadano. Journal of Science and Research. Revista Ciencia e Investigación, 5(1) pp149-164. https://zenodo.org/record/3599276\#.YRqa0IgzbIU

López, García, X., Rodríguez, Vázquez, A. I. y Pereira, Fariña, X. (2017). Competencias tecnológicas y nuevos perfiles profesionales: desafíos del periodismo actual. Comunicar, 25(53), 81-90 https://doi.org/10.3916/C53-2017-08

López-Meri, Amparo (2015). El impacto de Twitter en el periodismo: un estado de la cuestión. Revista de la Asociación Española de Investigación de la Comunicación, 2, 34-41. http://repositori.uji.es/xmlui/handle/10234/165677

Lorenz, Taylor (2018). Personal branding is more powerful than ever. Nieman Lab. http://www.niemanlab.org/2018/12/personal-branding-is-more-powerful-than-ever

Mantilla, K. (2013). Gendertrolling: Misogyny adapts to new media. Feminist Studies, 39(2). Pp 563570

Marauri, Castillo, I., Cantalapiedra, González, M J. y Álvarez-Fernández, C . (2018). Blog y Twitter, la combinación perfecta del comunicador digital: los casos de Escolar.net, El comidista y Mi mesa cojea. El profesional de la información, 27(2), 349-358. https://doi.org/10.3145/epi.2018.mar.13

Marín, Dueñas, P.P., Simancas, González, E. (2019). Los universitarios millenials: uso de redes sociales y relación con las marcas. Ámbito, 46, pp92-107 https://doi.org/10.12795/Ambitos.2019.i46.06

Marta, Lazo, C., Rodríguez, Rodríguez, J. M. y Peñalva, S. (2020). Competencias digitales en periodismo. Revisión sistemática de la literatura científica sobre nuevos perfiles profesionales del periodista. Revista Latina de Comunicación Social, 75,53-68. https://www.doi.org/10.4185/RLCS-2020-1416

Marta, C.; Rodríguez, J. y Peñalva, S. (2020). Competencias digitales en periodismo. Revisión sistemática de la literatura científica sobre nuevos perfiles profesionales del periodista. Revista Latina de Comunicación Social, 75, pp. 53-68 https://doi.org/10.4185/RLCS-2020-1416 
Martín, Algarra, M., Torregrosa, M. y Serrano-Puche, J. (2010). Un periodismo sin períodos: actualidad y tiempo en la era digital. XII Congreso de la Sociedad Española de Periodística (SEP). Valencia: $\quad$ Universidad Cardenal Herrera. https://dadun.unav.edu/bitstream/10171/16874/1/Un\%20periodismo\%20sin\%20periodos.pdf

Martín Granados, I. (2016). Telegram, herramienta de comunicación política. Asociación de Comunicación Política (ACOP). https://compolitica.com/telegram-herramienta-decomunicacionpolitica/.

Martínez-García, L. y Navarro Bosch, C. (2019). Características de los periodistas online españoles: consolidación de una profesión en un contexto de crisis económica. Revista Latina de Comunicación Social, 74, pp. 1014-1030 https://doi.org/10.4185/RLCS-2019-1369

McCrindle, M. (2014). The ABC of XYZ: Understanding the global generation. Sydney: UNSW Press

Mendiguren, Galdospín, T; Meso, Ayerdi, K y Pérez Dasilva, J (2011). El papel de las redes sociales en el proceso hacia una nueva arquitectura de los medios de comunicación social. La investigación en periodismo digital, pp. 432-444.

Menéndez Menéndez, M. I. (2007). Claves prácticas para la elaboración y revisión de textos periodísticos desde la perspectiva de género. En Plaza, J. y Delgado C. (Eds.). Género y Comunicación (pp. 149-168). Madrid: Fundamentos

Menéndez, Menéndez, M.I. (2017). Entre neomachismo y retrosexismo: antifeminismo en industrias culturales. Prisma Social, 2, pp 1-30

Meneses, J. (2016). El cuestionario. Universitat Oberta de Catalunya.

Meso, Ayerdi, K.; Mendiguren, Galdospín, T. and Pérez Dasilva, J. Á. (2015). The role of the community manager in the marketing strategies of Spanish companies most active in social media. Estudios sobre mensaje periodístico, v. 21, n. 1, pp. 385-402 https://doi.org/10.5209/rev_ESMP.2015.v21.n1.49101

Mompart, J. L. G., Lozano, J. F. G., y Sampio, D. P. (2015). Los periodistas españoles y la pérdida de la calidad de la información: el juicio profesional. Comunicar: Revista científica iberoamericana de comunicación y educación, (45), 143-150

Newman, N. (2020). The resurgence and importance of email newsletters. En Newman, N, Fletcher, R., Schulz, A., Andi, S., y Nielsen, R.K. Digital News Report 2020. https://www.digitalnewsreport.org/survey/2020/the-resurgence-and-importance-of-emailnewsletters/

Noguera Vivo, J.M. (2016). Metamedios y periodismo: revisión panorámica de los nuevos cibermedios. El profesional de la Información, 25, pp 341-350 https://doi.org/10.3145/epi.2016.may.03

Ortega Carrillo, J. A. (2017). La profesionalización del community manager: claves para una formación especializada de posgrado. Revista lasallista de investigación, v. 14, n. 1, pp. 217-232. https://doi.org/10.22507/rli.v14n1a19 
Ortega Cachón, I y Villanova, N. (2016). Generación Z: El último salto generacional. Atrevia, la consultora global de comunicación con espíritu latino. Business School Universidad de Deusto

Ortega, F; González Ispierto, B y Pérez Peláez, ME (2015) Audiencias en revolución, usos y consumos de las aplicaciones de los medios de comunicación en tabletas y teléfonos inteligentes. $\begin{array}{lllll}\text { Revista Latina de } & \text { Comunicación }\end{array}$ http://www.revistalatinacs.org/070/paper/1063/33es.html

Palomino Gonzales, M. (2019). Mecanismos de selección y verificación de información brindada por ciudadanos a través del WhatsApp en la producción informativa de canales de noticias peruanos. Estudio de caso: RPP Noticias y Canal N. Comunicación, 40, 35-52. https://doi.org/10.18566/comunica.n40.a03

Peer, Limor and Ksiazek, Thomas (2010). YouTube and the challenge to journalism. Journalism studies, v. 12, n. 1, pp. 45-63. https://doi.org/10.1080/1461670X.2010.511951

Pendergast, D. (2010). Getting to know the $\mathrm{Y}$ generation Tourism and generation Y. In: Benckendorff, P., Moscardo, G., Pendergast, D., Eds., Tourism and Generation Y, CAB International, Cambridge, 85-97.

Peña Fernández, S., Pérez Dasilva, J. Á., Meso Ayerdi, K., \& Larrondo Ureta, A. (2021). Social participation in the media: The dialogue of digital journalists with audiences. European Public and Social Innovation Review 6(1), 16-28

Peñafiel, Saiz, C. (2015). La comunicación transmedia en el campo del periodismo. Supervivencia en el ecosistema digital. Telos cuadernos de comunicación e innovación La era digital: balance y tendencias. Fundación Telefónica, 100, pp.84-88

Pérez, Soler, S. (2017). Periodismo y redes sociales. Claves para la gestión de contenidos digitales. Barcelona, UOC

Prensky, M. (2001). Digital Natives, Digital Immigrants. Part 1. On the Horizon. MCB University Press, 9 https://www.marcprensky.com/writing/Prensky\%20\%20Digital\%20Natives, \%20Digital\%20Immi grants\%20-\%20Part1.pdf

Raid, A. (2016, 16 de febrero). WhatsApp at 1 billion: How can journalists use the chat app for newsgathering?. First Draft. https://firstdraftnews.org/articles/whatsapp-at-1-billion-how-canjournalists-use-the-chat-app-for-newsgathering/

Rauchfleisch, A, Artho, X., Melag, J., Post, S. and Schrafer, M.S. (2017). How journalists verify user-generated content during terrorist crises. Analyzing Twitter communication during the Brussels attacks. https://doi.org/10.1177/2056305117717888

Rego, R. (2018). Changing Forms and Plataforms of Misogyny: Sexual Harassment of Woman Journalist on Twitter. Media Watch, 9 (3). pp437-446 
Rivas de Roca, R. (2020). Ética periodística para una información con perspectiva de género, Revista Internacional de Investigación en Comunicación aDResearch ESIC. $\mathrm{N}^{\mathrm{o}} 22$, Vol 22, Monográfico especial, 82 a 97. https://doi.org/10.7263/adresic-022-04

Rivero, Santamarina D., Meso, Ayerdi, K. y Peña, Fernández, S. (2015). La feminización de los estudios de Periodismo: análisis del caso español. Revista Latina de Comunicación Social, 70, pp. 566 a 583. http://www.revistalatinacs.org/070/paper/1060/30es.html

Rodríguez Fernández, O. (2012). Conviértete en experto en "Social Media”. Community Manager. Madrid, Anaya.

Rodríguez, Rubial, Antonio y García, López, Javier (2013). Uso y funciones de Twitter en periodistas españoles. Estudios sobre el mensaje periodístico, 19, 963-969. https://doi.org/10.5209/rev_ESMP.2013.v19.42181

Rojas, J.L., y Panal, A. (2017). El uso de Instagram en los medios de comunicación deportivos. Análisis comparado de Bleacher Report, L’équipe y Marca. Ámbitos, 38, 1-19.

Sánchez, H., y Martos J. (2020). Telegram como herramienta para periodistas: Percepción y uso. Revista de Comunicación, 19(2), 245-261. https://doi.org/10.26441/RC19.2-2020-A14

Sánchez de la Nieta, Hernández, M. (2013). Rasgos distintivos del periodismo en el scenario informativo digital. Hacia una revitalización de los valores clásicos de verdad, objetividad, independencia y servicio público. Tesis doctoral Universidad Complutense, Madrid

Sánchez de la Nieta, Hernández, M., Fuente, Cobo, C. (2020). Periodismo vs desinformación: la función social del periodista professional en la era de las fake news y la posverdad. Sintaxis 1 (4). Pp 1-18

Singer, J.B. (2005). The political j-blogger: Normalizing a new media form to fit old norms and practices. Journalism 6(2):173-198. https://doi.org/10.1177/1464884905051009

Singer, J.B.; Tharp, M.P. and Haruta, A. (1999). Online Staffers: Superstars or Second-class Citizens? Newspaper Research Journal, 20, pp. 29-48.

Sintes, Olivella, M. (2012). Redes sociales, vías para el fortalecimiento de la prensa local. En: Casero Ripollés, A., Fernández Beltrán, F. J. y González Molina, S. (eds.) La prensa local ante el reto digital.

Suárez Villegas, J.C. y Cruz Álvarez, J. (2016). Los dilemas deontológicos del uso de las redes sociales como fuentes de información. Análisis de la opinión de los periodistas de tres países. Revista Latina de Comunicación $\quad$ Social, $\quad 71, \quad 66-84$. http://www.revistalatinacs.org/071/paper/1084/04es.html

Tejedor Calvo, L Cervi (2017). Análisis de los estudios de Periodismo y Comunicación en las principales universidades del mundo. Competencias, objetivos y asignaturas. Revista Latina de Comunicación Social, 72, pp. 1.626 a 1.647. http://www.revistalatinacs.org/072paper/1238/88es.html 
Thorsen, E., y Jackson, D. (2018). Seven Characteristics Defining Online News Formats. Digital Journalism, 6(7), 847-868. https://doi.org/10.1080/21670811.2018.1468722

Túñez, López, J.-M., Toural, Bran, C. y Cacheiro, Requeijo, S. (2018). Uso de bots y algoritmos para automatizar la redacción de noticias: Percepción y actitudes de los periodistas en España. El Profesional de la Información, 27(4), pp. 750-758. https://doi.org/10.3145/epi.2018.jul.04

Ufarte, Ruiz, M.J. (2007). Las mujeres en el seno de la profesión periodística. De la discriminación a la inserción. Ámbitos, 16. pp 409-421

Vázquez, Herrero, J., Negreira, Rey, M. C., and López, García, X. (2020). Let's dance the news! How the news media are adapting to the logic of TikTok. Journalism, https://doi.org/10.1177/1464884920969092

Varona, Aramburu, D. y Sánchez, Muñoz, G. (2016). Las redes sociales como fuente de información periodística: Motivos para la desconfianza entre los periodistas españoles. El Profesional de la Información vol25, nº5. https://doi.org/10.3145/epi.2016.sep.10

Verón Lassa, J. J. y Sabés Turmo, F. (2008). Las nuevas tecnologías en la formación del periodista: una necesidad real e inmediata. Anàlisi: quaderns de comunicació i cultura, (36), 105-114.

Wu, Y. (2019). How Age Affects Journalists Adoption of Social Media as an Innovation, JournalismPractice, 13:5, 537557, https://doi.org/10.1080/17512786.2018.1511821

Wulf, T., Schneider, F. M., and Beckert, S. (2020). Watching players: An exploration of media

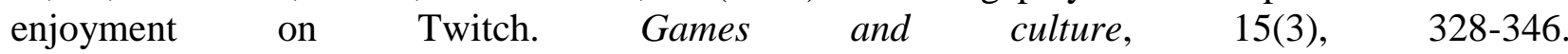
https://doi.org/10.1177/1555412018788161

Yamamoto, Masahiro; Nah, Seungahn and Chung, Deborah S. (2017). Conceptualizing Citizen Journalism: US News Editors' Views. International Journal of Communication, 11: 684-700. https://doi.org/10.1177/1464884916686596

Yepes Jiménez, C. R. (2021). Cultura cívica, periodismo y redes sociales digitales: promesas, debilidades, transformaciones y retos. Tesis Doctoral, Universidad EAFIT https://repository.eafit.edu.co/handle/10784/29619

\section{AUTORAS/ES:}

\section{María Ganzabal Learreta}

María Ganzabal, doctora desde 1996, ha sido desde 2003 profesora tanto del Departamento de Comunicación Audiovisual como, desde 2009, del Departamento de Periodismo de la Universidad del País Vasco. Después de trabajar en varias Agencias de Comunicación y en la revista americana New Woman (Nueva York) ha sido coordinadora del Área de Comunicación del Máster de Estudios Feministas y de Género de la Universidad del País Vasco y ha impartido clases en este postgrado desde 2008. Sus estudios en múltiples equipos de investigación siempre han estado orientados hacia el periodismo digital, plataformas sociales, periodismo participativo, audiencias y temas sociales además de los relacionados con el género. Los artículos sobre estos aspectos se pueden ver publicados en revistas con alto índice de impacto.

maria.ganzabal@ehu.eus 
ORCID ID: https://orcid.org/0000-0002-4231-402X

Google Scholar: https://scholar.google.com/citations?user=57okVKcAAAAJ\&hl=en

\section{Koldobika Meso Ayerdi}

En la actualidad es profesor titular de la Facultad de Ciencias Sociales y de la Comunicación de la Universidad del País Vasco, donde imparte las asignaturas Redacción Ciberperiodística y Bases teóricas y metodología de la investigación en ciberperiodismo, ésta última en el Master de Investigación Social de la UPV/EHU. También ha impartido materias como Modelos de los Medios de Comunicación e Introducción al Periodismo en Internet (en el Campus Virtual). Es autor de varios libros sobre periodismo en Internet y ha publicado más de cuarenta artículos sobre la materia en revistas indexadas de prestigio. También es coautor de un manual sobre la materia de Redacción Ciberperiodística. Actualmente es el director del Departamento de Periodismo de la UPV-EHU y codirige el proyecto "Audiencias activas y viralización y transformación de los mensajes periodísticos" (CSO2015-64955-C4-4-R), financiado por el Plan Nacional del I+D+I, del Ministerio de Economía y Competitividad, y por el Fondo Europeo de Desarrollo Regional (FEDER). Asimismo, es miembro del grupo consolidado de investigación Gureiker.

koldo.meso@ehu.eus

ORCID ID: http://orcid.org/0000-0002-0400-133X

Google Scholar: https://scholar.google.es/citations?user=daFlEQIAAAAJ\&hl=es\&oi=ao

\section{Jesús Ángel Pérez Dasilva}

Profesor en el departamento de Periodismo de la Facultad de Ciencias Sociales y de la Comunicación de la Universidad del País Vasco. Es miembro el grupo de investigación Gureiker (grupo A del sistema universitario vasco). Ha participado en 20 proyectos de investigación siendo en 5 de ellos el investigador principal. Es coautor de 46 artículos científicos, 32 capítulos de libro y de 70 contribuciones en congresos nacionales e internacionales. Cuenta con 3 sexenios reconocidos por la CNEAI. Sus líneas de investigación se centran en la transformación digital del periodismo. Sus últimos trabajos están relacionados con la audiencia, la interactividad y las redes sociales.

jesusangel.perez@ehu.eus

ORCID ID: http://orcid.org/0000-0002-3383-4859

Google Scholar: https://scholar.google.es/citations?user=NANienYAAAAJ\&hl=es

\section{Terese Mendiguren Galdospín}

Terese Mendiguren es Doctora en Ciencias de la Información por la Universidad del País Vasco y Licenciada en Comunicación Audiovisual. Imparte docencia en el grado de Periodismo de la UPV/EHU, en el Máster de Periodismo Multimedia de El Correo y en el Máster de Comunicación Multimedia de EITB. Es Vicedecana de Comunicación y Relaciones Externas de la Facultad de Ciencias Sociales y de la Comunicación. Como investigadora ha participado en 15 proyectos de investigación y ha publicado una veintena de artículos en revistas académicas de prestigio incluidas en bases de datos como JCR o SCOPUS. Además, ha impartido conferencias relacionadas con la innovación educativa o el periodismo participativo. Actualmente es miembro del proyecto "Noticias, redes y usuarios en el sistema híbrido de medios" financiado por el Ministerio de Economía y Competitividad y del Grupo consolidado de investigación Gureiker. En su faceta profesional ha trabajado como redactora y coordinadora de programas de ETB y Bilbovisión, cadena esta última donde también ha ejercido de reportera, locutora y presentadora de diversos espacios de entretenimiento y cultura.

tererse.mendiguren@eu.eus

ORCID ID: http://orcid.org/0000-0003-3092-6608

Google Scholar: https://scholar.google.es/citations?user=EeZ1X9MAAAAJ\&hl=es\&oi=ao 